\title{
Impact toughness of a gradient hardened layer of Cr5Mo1V steel treated by laser shock peening
}

\author{
Weiguang $\mathrm{Xia}^{1} \cdot \mathrm{Lei}^{\mathrm{Li}}{ }^{2}$ - Yanpeng $\mathrm{Wei}^{1} \cdot \mathrm{Aimin}_{\mathrm{Zhao}}{ }^{3} \cdot \mathrm{Yacong}_{\mathrm{Guo}}{ }^{1}$. \\ Chenguang Huang ${ }^{1}$ • Hongxiang Yin $^{3}$ • Lingchen Zhang ${ }^{4}$
}

Received: 8 March 2015 / Revised: 6 April 2015 / Accepted: 3 May 2015 / Published online: 21 September 2015

(C) The Chinese Society of Theoretical and Applied Mechanics; Institute of Mechanics, Chinese Academy of Sciences and Springer-Verlag Berlin Heidelberg 2015

\begin{abstract}
Laser shock peening (LSP) is a widely used surface treatment technique that can effectively improve the fatigue life and impact toughness of metal parts. Cr5Mo1V steel exhibits a gradient hardened layer after a LSP process. A new method is proposed to estimate the impact toughness that considers the changing mechanical properties in the gradient hardened layer. Assuming a linearly gradient distribution of impact toughness, the parameters controlling the impact toughness of the gradient hardened layer were given. The influences of laser power densities and the number of laser shots on the impact toughness were investigated. The impact toughness of the laser peened layer improves compared with an untreated specimen, and the impact toughness increases with the laser power densities and decreases with the number of laser shots. Through the fracture morphology analysis by a scanning electron microscope, we established that the Cr5Mo1V steel was fractured by the cleavage fracture mechanism combined with a few dimples. The increase in the impact toughness of the material after LSP is observed because of the decreased dimension and increased fraction of the cleavage fracture in the gradient hardened layer.
\end{abstract}

Yanpeng Wei

weiyanpeng@imech.ac.cn

1 Key Laboratory for Mechanics in Fluid Solid Coupling Systems, Institute of Mechanics, Chinese Academy of Sciences, Beijing 100190, China

2 Sinosteel Scie-tech Development Company Limited, Beijing 100080, China

3 Metallurgical Engineering Research Institute, University of Science and Technology Beijing, Beijing 100083, China

4 Center of Library and Information, Institute of Mechanics, Chinese Academy of Sciences, Beijing 100190, China
Keywords Laser shock peening - Gradient hardened layer - Plastically affected depth - Impact toughness . Cleavage fracture

\section{Introduction}

Laser shock peening (LSP) is an advanced surface treatment technique that has been successfully applied to improve the wear resistance and impact performance of metallic components [1-3]. During an LSP process, a shock wave with high-amplitude pressure is generated and propagates into the target material through the interaction of a high-power density pulsed laser and a thin absorption layer on the target surface. Plastic deformation occurs, and plenty of dislocations are generated near the material surface once the pressure of the shock wave exceeds the Hugoniot elastic limit (HEL) of the material. Thus, residual compressive stresses are induced in the shocked region, resulting in a hardened layer near the target surface, which displays good performance considering wear and impact. It was found by Yasnii et al. [4] that the impact toughness of $15 \mathrm{Kh} 13 \mathrm{MF}$ steel increases up to twofold after LSP with a power density ranging from $5 \times 10^{8}$ to $2 \times 10^{9} \mathrm{~W} \cdot \mathrm{cm}^{-2}$. The mechanism of the increase of impact toughness is mainly from two aspects: residual stresses and dislocations in the hardened layer [1,5-9]. Prefabricated residual compressive stress can improve the stress threshold of crack growth. Using a laser quenching technique, Kong and Zhang [6] introduced residual compressive stresses into the $40 \mathrm{CrNiMo}$ steel, and the residual compressive stress can effectively retrain crack extension and improve impact toughness of the sample. Additionally, the refinement of crystalline grain or the generation of dislocation and deformation twinning can effectively restrain the generation of a 
crack. By reducing the mean grain size of a $\mathrm{Mg}-3 \mathrm{Al}-\mathrm{Zn}$ alloy to less than $3 \mu \mathrm{m}$, Liao et al. [7] reported that the impact toughness is greatly improved due to enhancement of the dynamic strength and dynamic plastic deformation ability. It was reported by Mats et al. [9] that the increase of the impact toughness for the steel 15Kh2NMFA upon high-temperature ultrasonic treatment of various durations is due to the formation of a uniform defect structure. For the LSP processing technology, the mechanical properties of the hardened layer are not uniform $[1,2,10-12]$. By the micro-hardness tests across the LSP peened layer, Peyre et al. [10] reported that the hardness decreases gradually from surface to the base material. Using the X-ray diffraction (XRD) measurement, Dane et al. [11] reported that the residual compressive stresses induced by LSP process are gradually decreased along the depth and finally reach a level identical to the base material. No discontinuity surface is generated at the interface between the hardened layer and base material. Thus, the laser peened layer can be seen as a gradient hardened layer (GHL) whose impact toughness needs to be investigated comprehensively.

Although the integral impact toughness of a structural component is the main concern in the engineering application, the local impact toughness of GHL given in this study has its advantages. When the local impact toughness of a configuration is determined, the integral impact toughness can be calculated through a specific model. Even more important, the integral impact toughness of various geometric configurations can also be predicted through the local impact toughness of GHL for the same processing parameters that may save much cost of detection.

In this paper, the laser peened layer of $\mathrm{Cr} 5 \mathrm{Mo} 1 \mathrm{~V}$ steel is considered to be a GHL. The control parameters of impact toughness of GHL are defined for a linearly gradient distribution. The value of the control parameters is experimentally determined from Charpy impact tests and hardness tests using an empirical equation. Additionally, the influences of laser power densities and the number of laser shots on the impact toughness were investigated. The fracture mechanism of GHL was characterized on a scanning electron microscope (SEM).

\section{Experimental}

\subsection{Materials}

Cr5Mo1V steel materials were provided by the University of Science and Technology of Beijing (China). The nominal alloy composition is shown in Table 1 . The steel was heattreated in a furnace at $850-870{ }^{\circ} \mathrm{C}$ for $3-4 \mathrm{~h}$, and then cooled to $740-760{ }^{\circ} \mathrm{C}$ for $3-4 \mathrm{~h}$, and then cooled in the furnace to $50{ }^{\circ} \mathrm{C}$, and finally cooled in the air. The microstructure consists of bimodal crystalline grains whose size varies from 15 to $90 \mu \mathrm{m}$ (see Fig. 1). Prior to LSP, the specimen surface
Table 1 The composition of Cr5Mo1V steel (wt \%)

\begin{tabular}{llllllll}
\hline Composite & $\mathrm{C}$ & $\mathrm{Cr}$ & $\mathrm{Mo}$ & $\mathrm{Si}$ & $\mathrm{V}$ & $\mathrm{W}$ & $\mathrm{Fe}$ \\
\hline$\%$ & 0.50 & 5.00 & 1.20 & 1.00 & 0.45 & 1.00 & ${ }^{*} \mathrm{Bal}$. \\
\hline
\end{tabular}

* Balance

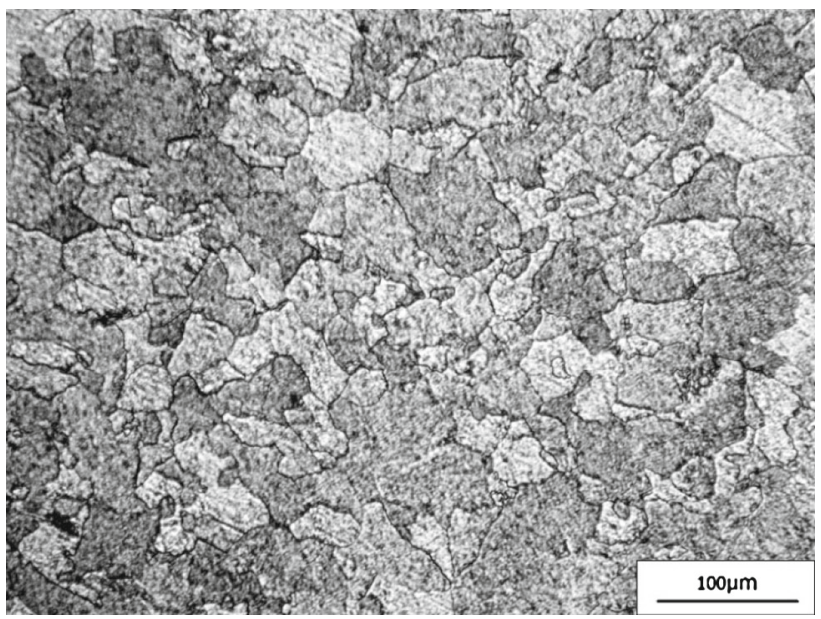

Fig. 1 The microstructure of Cr5Mo1V steel

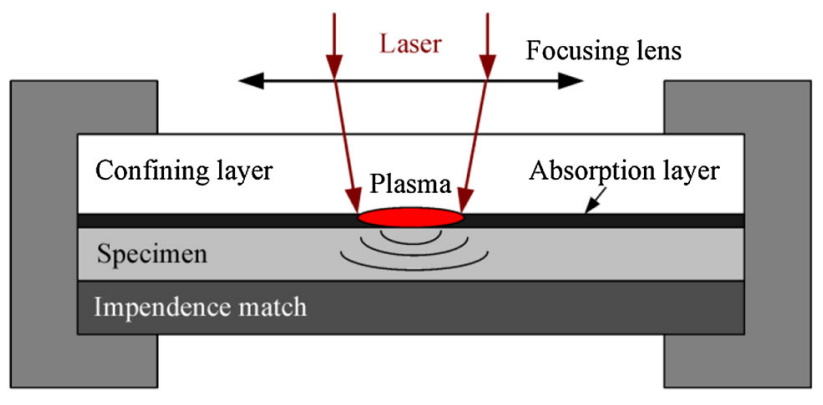

Fig. 2 The schematic of LSP experiment

was ground with sandpaper and finally polished with $50 \mathrm{~nm}$ $\mathrm{SiO}_{2}$ of turbid liquid.

\subsection{LSP experiment}

Figure 2 shows the schematic of the LSP experiment. The shocked surface of the Cr5Mo1V steel sample is glued with an aluminum foil ( $40 \mu \mathrm{m}$ thick) as an ablative overlay, and confined by flowing water against the laser irradiation. The aluminum foil is meanwhile used to increase the shock wave intensity and to protect the sample surface from laser ablation and melting. The flowing water is used to confine the expanding plasma to obtain higher shock pressure. Another Cr5Mo1V steel sample was attached to the back of the Cr5Mo1V steel specimen to match the impendence. A Q-switched high power Nd: YAG pulsed laser (Spectra Physics) operating at $1064 \mathrm{~nm}$ wavelength was used in the LSP experiment. The maximum output energy of a single 
laser pulse is $2.4 \mathrm{~J}$ and the pulse width (full width at half maximum) is about $10 \mathrm{~ns}$. A focusing lens was utilized to adjust the laser spot size in order to obtain different laser power densities. The laser power density varied from 2.6 to $4.4 \mathrm{GW} \cdot \mathrm{cm}^{-2}$.

\subsection{Property characterizations}

The micro-hardness of the LSP-treated specimen was measured by a MH-6 micro-hardness tester with a load of $200 \mathrm{~g}$ and a holding time of $10 \mathrm{~s}$ at room temperature. The depth of the GHL of the Cr5Mo1V specimen after LSP was obtained through a micro-hardness distribution along the cross-section of LSP-treated specimen. The surface micro-hardness of the shocked region was measured to characterize the surface strengthening effect.

At room temperature, the Charpy impact test was performed using an impact testing machine with a JBDW-300D pendulum bob for samples treated with LSP. The Charpy specimens were prepared according to the GB/T229 standard test method for Charpy pendulum impact of metallic materials [13]. As the laser spot size is small (at the level of 3 $\mathrm{mm}$ ), massive laser shots were applied on the sample surface in order to obtain a large laser-treated area. The overlapping ratio was $60 \%$ controlled by an $x-y$ table. The shocked region is shown in Fig. 3, with a dimension of $10 \mathrm{~mm} \times 8 \mathrm{~mm}$. Both of the two sides are peened by LSP. To obtain a greater depth of the peened layer, different numbers of laser shots were used, varying from one to five shots. After the impact test, the impact energy of each sample was recorded.

\subsection{Microstructure observations}

A scanning electron microscope (Nova NanoSEM operated at $10 \mathrm{kV}$ ) was used to characterize the Charpy impact fracture morphology.

\section{Results and discussion}

\subsection{Modeling of the impact toughness of a gradient hardened layer}

The classical impact toughness is defined as $a_{k}=A_{k} / A$ under the assumption that mechanical properties in the crosssection are uniform, where $A_{k}$ is the impact work, and $A$ is the cross-section area [14-17]. Moreover, Zhou et al. [14] reported that the average impact toughness of $2 \mathrm{Crl} 3$ martensite stainless steel increased as the laser power density increased (within an appropriate range). However, the material treated by LSP presents nonuniformity, and the increase in the impact toughness is mainly attributed to the hardened layer. However, the classical equation cannot reflect the impact toughness of the gradient hardened layer because of the dimensional effect.

The distribution of impact toughness of GHL can be perceived as a function of depth. To simplify the model, the function is assumed to be linear according to the hardness and residual stress distribution tests across the peened layer section of former studies $[10,11]$. By measuring the microhardness across the cross-section of the GHL, Peyre et al. [10] found that the hardnesses decreases almost linearly along the depth and finally reach a level identical to the base material. The impact toughness is highest at the surface of the specimen and decreases linearly along the GHL. The highest impact toughness of GHL is denoted as $a_{k_{1}}$ in the top surface. The impact toughness of the base material is denoted as $a_{k_{0}}$. Thus, the gradient of the impact toughness from surface to the boundary, denoted as $k$, can be calculated as follows:

$k=\frac{a_{k_{1}}-a_{k_{0}}}{h}$

where $h$ is the depth of the GHL layer after LSP. Therefore, the impact toughness during the peened layer can be calculated as follows:

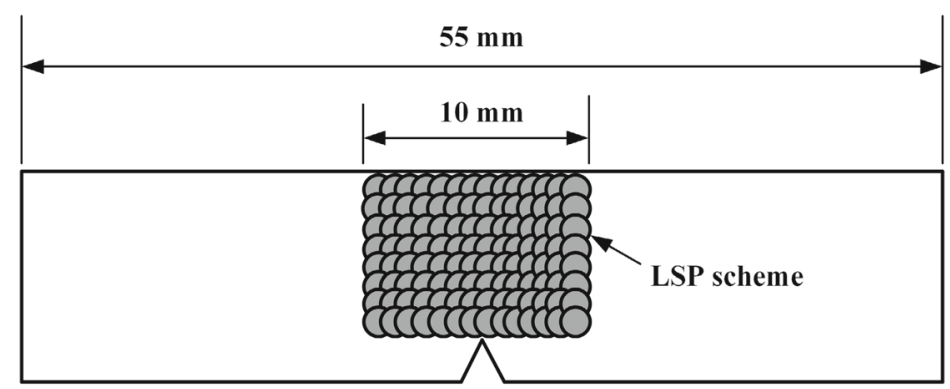

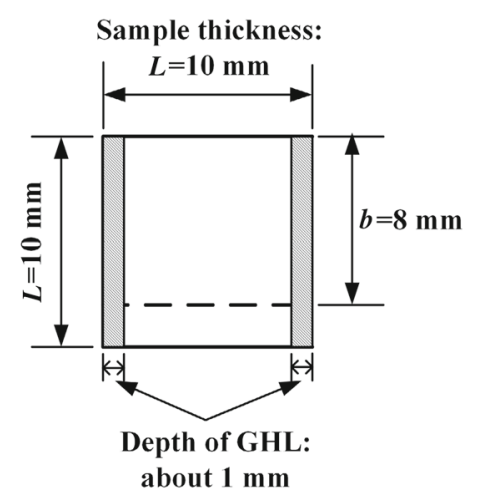

Fig. 3 Scheme of the laser shock peening and dimensions of the specimen 


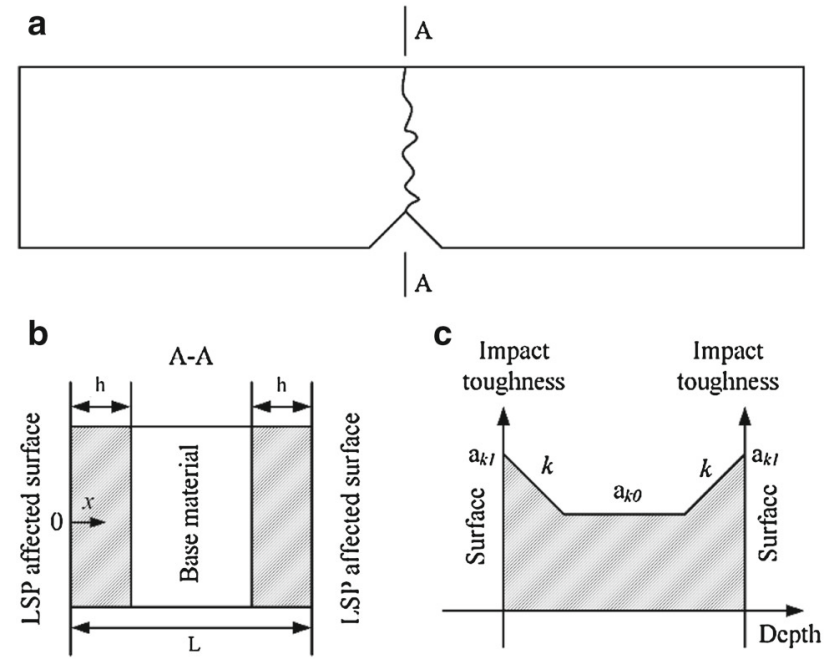

Fig. 4 Modeling the impact toughness of the GHL. a The schematic of a fracture of the Charpy specimen. $\mathbf{b}$ The cross-section of a laser peened layer. $\mathbf{c}$ The distribution of the impact toughness at the cross-section of the peened layer

$a_{k}=a_{k_{1}}-k x$

where $x$ is the distance from the surface to the internal peened layer, as shown in Fig. 4. The parameters controlling the impact toughness of the gradient hardened layer are the surface impact toughness, $a_{k_{1}}$, and the gradient, $k$, for the assumption of linearly gradient distribution of impact toughness during the peened layer.

Charpy impact tests are widely used to determine the impact toughness of material [18-20]. Figure 4a shows the schematic of fracture of a Charpy specimen at impact load. Figure $4 \mathrm{~b}$ shows the cross-section including the laser peened layer and the base material. Figure $4 \mathrm{c}$ shows the distribution of the impact toughness at the cross-section. To simplify the model, several assumptions are drawn:

(1) The crack propagation surface is always perpendicular to the head surface.

(2) The mechanical properties are assumed to have a linearly gradient distribution during the laser peened layer. The properties of the GHL boundary are equal to the properties of the base material.

During the Charpy impact tests, the impact work is obtained. The fractures of both the GHL and the base material contribute to the impact work. Therefore, the surface impact toughness after LSP can be calculated as follows:

$2 \int_{0}^{h}\left(a_{k_{1}}-k x\right) b \mathrm{~d} x+a_{k_{0}} b(L-2 h)=A_{k}$, where, $b$ is the distance from the notch to the undersurface (see Fig. 3), and $A_{k}$ is the impact work. The impact toughness of the base material, $a_{k_{0}}$, can be obtained from an untreated sample. The depth of GHL, $h$, has a significant influence on the surface impact toughness, $\mathrm{a}_{k 1}$, and the gradient, $k$, in Eqs. (1) and (3). The depth of GHL, $h$, can be obtained from the distribution of the micro-hardness along the cross-section of a laser peened specimen. Therefore, the surface impact toughness after LSP can be calculated from Eqs. (1) and (3).

\subsection{Depth of the GHL}

The depth of GHL can be obtained through the microhardness distribution along the cross-section of laser peened sample [10-12]. According to Chen et al. [21] and Carlsson and Larsson [22], the induced residual compressive stress can enhance the hardness of material. Meanwhile, the improvement of impact toughness is also related to the compressive residual stress $[6,8]$. So, we speculate that the gradients of the hardness and impact toughness have the similar distribution. Thus, the hardness along the cross-section of peened sample can be used to determine the depth of GHL. Using the micro-hardness test, the depth of GHL of the Cr5Mo1V steel treated with different laser power densities and different numbers of shots was measured, as shown in Fig. 5a, b. For the sample test at a laser power density of $3.8 \mathrm{GW} \cdot \mathrm{cm}^{-2}$, the micro-hardness test along the cross-section of a laser-treated sample shows that the micro-hardness increases at the surface of the GHL, and then gradually decreases to the value of the untreated region at a depth of $(1.00 \pm 0.05) \mathrm{mm}$, as shown in Fig. 5a. The result indicates that the thickness of GHL is $(1.00 \pm 0.05) \mathrm{mm}$ at a laser power density of $3.8 \mathrm{GW} \cdot \mathrm{cm}^{-2}$. The depth of the GHL at other laser parameters can be obtained through this method. The relationship between the depth of the GHL and laser power density is shown in Fig. 6a. The depth of the GHL increases with laser power density for laser power densities lower than $3.8 \mathrm{GW} \cdot \mathrm{cm}^{-2}$ and slightly decreases at laser power densities higher than $3.8 \mathrm{GW} \cdot \mathrm{cm}^{-2}$. This behavior is because the laser induced shock pressure is proportional to the square root of laser power density according to Fabbro's model [23], i.e., the higher laser power density is, the higher the laser induced shock pressure is. According to the research of Ballard et al. [24], plastically affected depth is proportional to the difference between shock pressure and HEL. Thus, higher shock pressure induces deeper plastically affected depth. That is why the depth of GHL increases with laser power density when the laser power density is lower than $3.8 \mathrm{GW} \cdot \mathrm{cm}^{-2}$. However, when the laser power density exceeds a critical value, the surface of the confining overlay will become opaque to the laser. Thus, the effective laser energy on the shocked surface will decrease. As a result, the depth of GHL will decrease. That is why the depth of GHL 

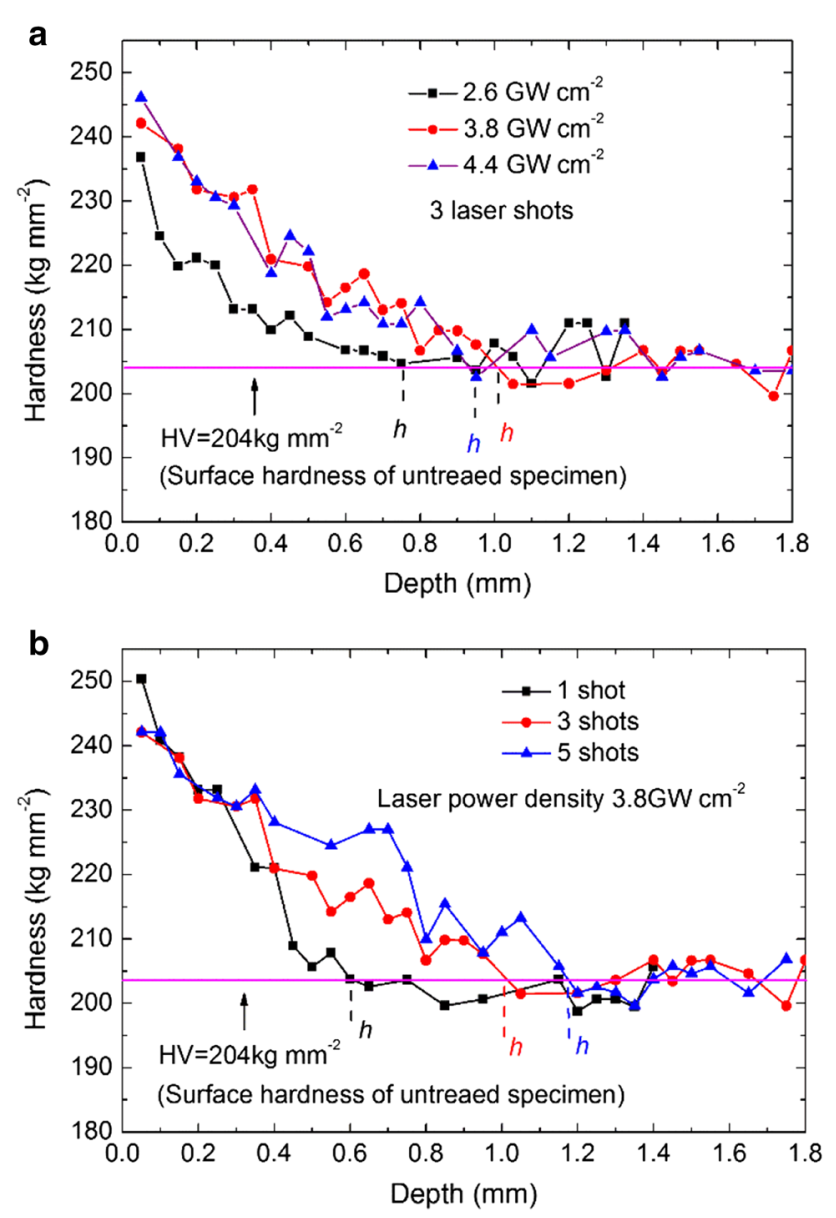

Fig. 5 Hardness as a function of depth on the cross-section of a peened sample: a different laser power densities and $\mathbf{b}$ different number of laser shots

slightly decreases while the laser power density increases to $4.4 \mathrm{GW} \cdot \mathrm{cm}^{-2}$.

Figure $6 \mathrm{~b}$ shows the relationship between the depth of the GHL and the number of laser shots. The depth of GHL is proportional to the laser shots, which is consistent with the experimental results of Dane et al. [11] and Masse et al. [25]. It was found by Dane et al. [11] that the depth of residual compressive stresses generated by two successive laser shots is higher than that of a single shot. Also, Masse et al. [25] found that the plastically affected depth increases from 0.86 to $1.80 \mathrm{~mm}$ when the number of laser shots increases from one to three. So the more the number of laser shots are, the higher the depth of GHL is.

\subsection{Impact toughness}

From the Charpy impact tests, the impact work is shown in Table 2. The impact work increases with increasing laser power densities when the laser power density is lower than $3.8 \mathrm{GW} \cdot \mathrm{cm}^{-2}$. When the laser power density exceeds
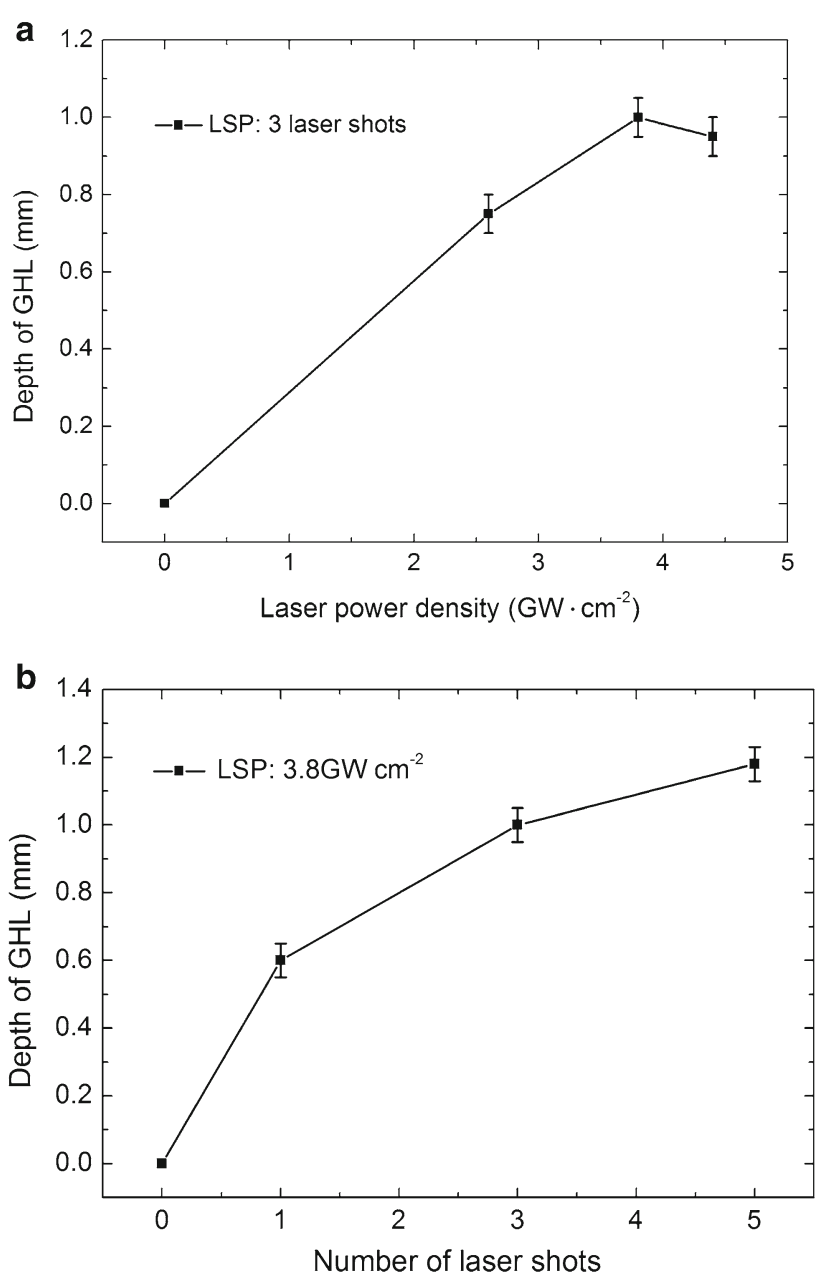

Fig. 6 The plastically affected depth of different laser power densities and numbers of laser shots: a different laser power densities and $\mathbf{b}$ different numbers of laser shots

$3.8 \mathrm{GW} \cdot \mathrm{cm}^{-2}$, the impact work is almost unchanged. The depth of the GHL also has the identical trend with the impact work. Based on Eqs. (1)-(3) combined with the depth of the GHL, the surface impact toughness, $a_{k_{1}}$, and the gradient, $k$, of the peened samples can be calculated as shown in Fig. 7a. The impact toughness and the gradient $k$ both increase as the laser power density increases from 2.6 to $4.4 \mathrm{GW} \cdot \mathrm{cm}^{-2}$. This increase is consistent with Zhou et al. [14] whose results demonstrate that the impact toughness of the $2 \mathrm{Crl} 3$ martensite stainless steel increases with increasing laser power densities when the laser power density is lower than $8.57 \mathrm{GW} \cdot \mathrm{cm}^{-2}$. The reason for this increase is due to the residual compressive stress induced by a laser induced shock which can restrain the growth of the crack $[1,2,14,26]$. As the residual compressive stress increases with increasing laser power densities within an appropriate range, the surface impact toughness increases with the laser power density. This can be reflected through the surface hardness after 
Table 2 Characteristics of the GHL with different laser power densities

\begin{tabular}{llllll}
\hline $\begin{array}{l}\text { Laser power density } \\
\left(\mathrm{GW} \cdot \mathrm{cm}^{-2}\right)\end{array}$ & $\begin{array}{l}\text { Depth of GHL } \\
{[h(\mathrm{~mm})]}\end{array}$ & $\begin{array}{l}\text { Impact work } \\
{\left[\mathrm{A}_{k}(\mathrm{~J})\right]}\end{array}$ & $\begin{array}{l}\text { Surface impact toughness } \\
{\left[\mathrm{a}_{k}\left(\mathrm{~J} \cdot \mathrm{cm}^{-2}\right)\right]}\end{array}$ & $\begin{array}{l}\text { The } \\
{\left[\mathrm{k}\left(\mathrm{J} \cdot \mathrm{cm}^{-3}\right)\right]}\end{array}$ & $\begin{array}{l}\text { gradient } \\
(\mathrm{kg} \cdot \mathrm{mm}\end{array}$ \\
\hline Untreated & 0 & 2.97 & 3.71 & 0 & 204.0 \\
2.6 & $0.75 \pm 0.05$ & 3.13 & $6.38 \pm 0.19$ & $35.56 \pm 5.26$ & 236.8 \\
3.8 & $1.00 \pm 0.05$ & 3.43 & $9.46 \pm 0.30$ & $57.50 \pm 6.21$ & 242.1 \\
4.4 & $0.95 \pm 0.05$ & 3.42 & $9.63 \pm 0.33$ & $62.33 \pm 7.11$ & 246.1 \\
\hline
\end{tabular}
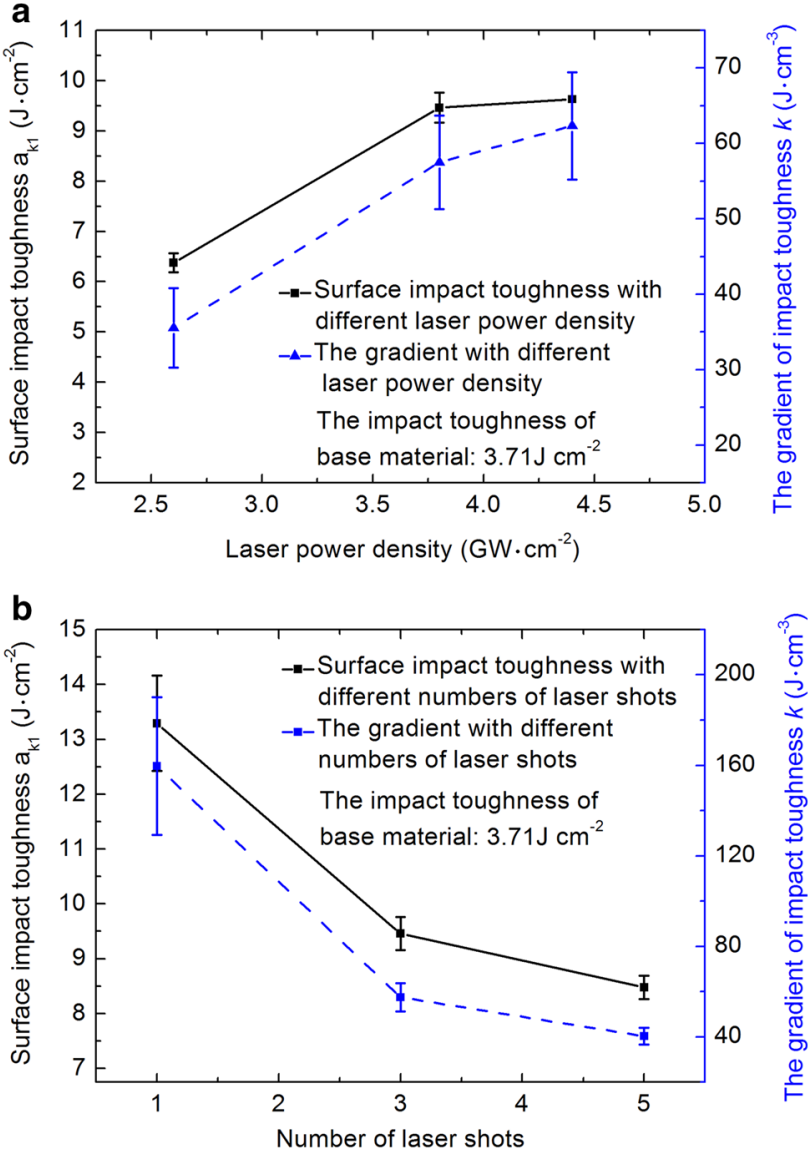

Fig. 7 Impact toughness, $a_{k_{1}}$, and the gradient, $k$, for different laser power densities and different numbers of laser shots: a different laser power densities and $\mathbf{b}$ different numbers of laser shots

LSP. In Table 2, the surface hardness increases from 236.8 to $246.1 \mathrm{~kg} \cdot \mathrm{mm}^{-2}$ as the laser power density increases from 2.6 to $4.4 \mathrm{GW} \cdot \mathrm{cm}^{-2}$, which has the identical trend with the experimental results of Clauer and Fairand [27]. Clauer and Fairand [27] found that the average surface hardness of 2024-T351 increases with peak shock pressure while the peak pressure is proportional to the square root of laser power density. The increase in the gradient can be ascribed to the fact that the increasing rate of impact toughness is higher than the increasing rate of the depth of the GHL according to Eq. (1).
The impact work with different numbers of laser shots is shown in Table 3. Comparing with untreated samples, the impact work increases after LSP. The increase in the impact work shows no dependence on the numbers of laser shots. According to Eqs. (1)-(3) and the depth of the GHL, the impact toughness, $a_{k_{1}}$, and the gradient, $k$, of a peened specimen can be calculated as shown in Fig. 7b. As the impact work is almost unchanged, and the depth of the GHL increases with the numbers of laser shots, the surface impact toughness decreases with the numbers of laser shots according to Eq. (3). The gradient $k$ of the peened samples also decreases with increasing numbers of laser shots according to Eq. (1). Using finite element analysis to simulate the LSP process of 35CD4 steel alloy, Ding and Ye [28] reported that the surface compressive residual stress is almost unchanged while the plastically affected depth increases from 0.74 to $1.4 \mathrm{~mm}$ when the numbers of laser shots increases from one to three. Surface compressive residual stress plays an important role on the magnitude of surface impact toughness through restraining the generation and growth of crack. As a result, the gradient $k$ decreases with increasing the number of laser shot according to our model, due to the fact that the depth of GHL increases rapidly while the surface compressive residual stress is almost unchanged with increasing the number of laser shots.

\subsection{Mechanisms of fracture of treated specimens}

Figure 8 shows the fracture mechanism of specimens treated with laser induced shock at the laser power density of $4.4 \mathrm{GW} \cdot \mathrm{cm}^{-2}$ with three laser shots. Figure $8 \mathrm{a}$ shows the fracture morphology from an LSP-treated surface to an untreated region. The main mechanism of fracture is cleavage fracture combined with a few dimples. The microstructure of a fracture surface is similar to a river pattern. The dimension of the cleavage fracture decreases from the surface to the untreated region. Cleavage fracture with smaller dimensions can absorb more energy during fracture, resulting in higher impact work. Figure $8 \mathrm{~b}-\mathrm{d}$ show the morphology of the cleavage fractures from untreated region to the LSP treated surface. Figure $8 \mathrm{~b}$ shows the morphology of the cleavage fractures of the untreated region. The number of cleavage fractures is relatively low and the dimensions of cleavage 
Table 3 Characteristics of GHL with different numbers of laser shots

\begin{tabular}{lllcll}
\hline $\begin{array}{l}\text { Numbers of laser } \\
\text { shots }\left(\mathrm{GW} \cdot \mathrm{cm}^{-2}\right)\end{array}$ & $\begin{array}{l}\text { Depth of GHL } \\
{[h(\mathrm{~mm})]}\end{array}$ & $\begin{array}{l}\text { Impact work } \\
{\left[A_{k}(\mathrm{~J})\right]}\end{array}$ & $\begin{array}{l}\text { Surface impact } \\
\text { toughness } \\
{\left[a_{k_{1}}\left(\mathrm{~J} \cdot \mathrm{cm}^{-2}\right)\right]}\end{array}$ & $\begin{array}{l}\text { The gradient } \\
\left.\left[\mathrm{k}(\mathrm{J} \cdot \mathrm{cm})^{-3}\right)\right]\end{array}$ & $\begin{array}{l}\text { Surface hardness } \\
(\mathrm{kg} \cdot \mathrm{mm}\end{array}$ \\
\hline Untreated & 0 & 3.71 & 0 & 204.0 \\
1 & $0.60 \pm 0.05$ & 3.43 & $13.29 \pm 0.87$ & $159.72 \pm 30.36$ & 250.4 \\
3 & $1.00 \pm 0.05$ & 3.43 & $9.46 \pm 0.30$ & $57.50 \pm 6.21$ & 242.1 \\
5 & $1.18 \pm 0.05$ & 3.42 & $8.48 \pm 0.21$ & $40.40 \pm 3.65$ & 242.1 \\
\hline
\end{tabular}
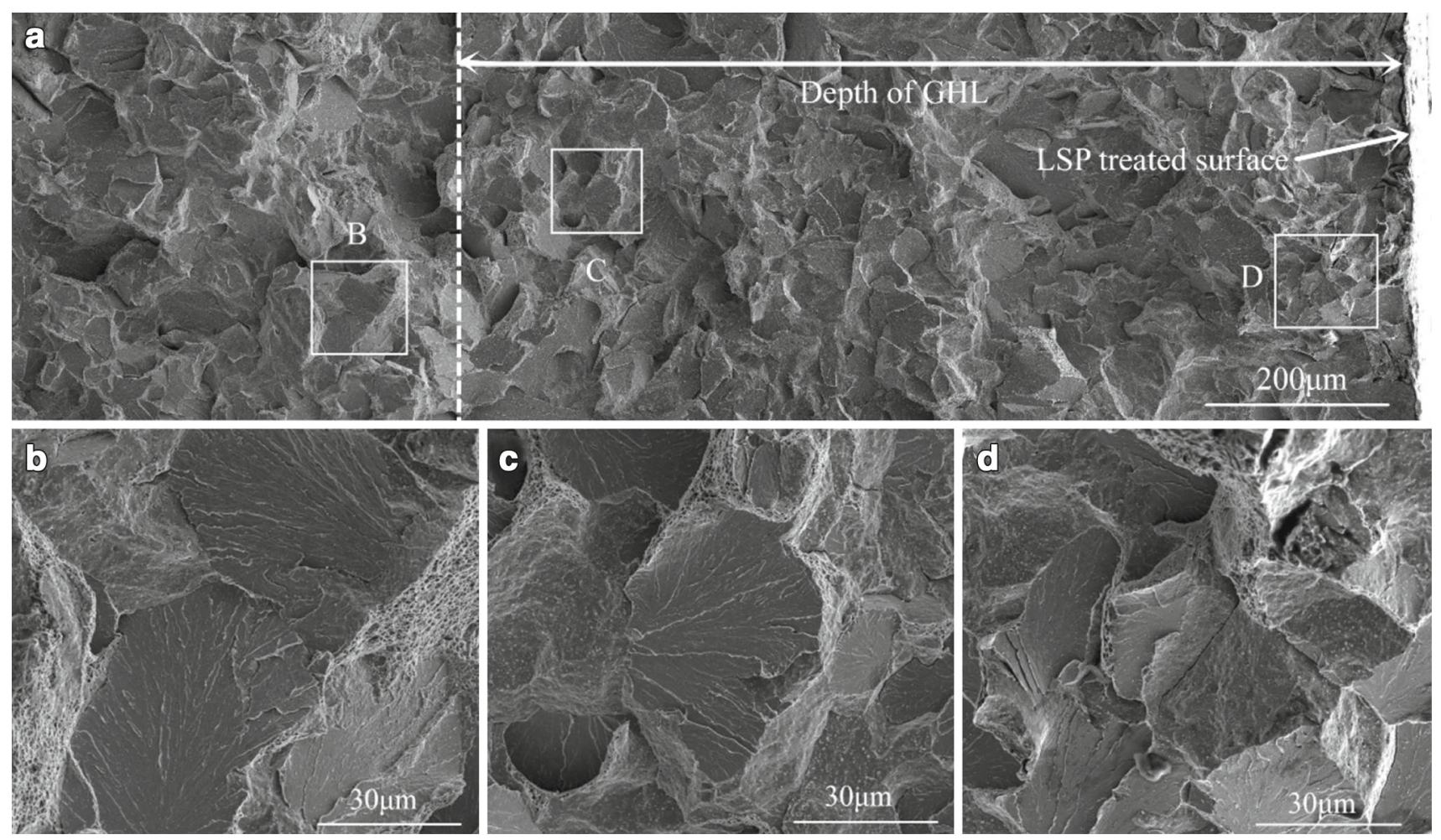

Fig. 8 Fracture morphology of a laser peened Charpy specimen for a laser power density of $4.4 \mathrm{GW} \cdot \mathrm{cm}^{-2}$ and three laser shots. a Fracture morphology from the LSP-treated surface to the untreated region. b Amplified image of cleavage fractures from region B of the untreated region. c Amplified image of cleavage fractures from region C in the GHL. d Amplified image of cleavage fractures from region D beneath the LSP-treated surface

fractures are large, at the level of $80-90 \mu \mathrm{m}$. Figure 8c shows the morphology of the cleavage fractures at the region away from the surface of the GHL. The number of cleavage fractures increases, and the dimension of the cleavage fracture (at the level of 50-60 $\mu \mathrm{m}$ ) is smaller compared with the untreated region. Therefore, the impact toughness in the GHL is higher than the untreated region toughness as the increased cleavage fractures can absorb more energy during the impact. Figure 8d shows the morphology of the cleavage fractures beneath the surface of the GHL. This region has the largest number of cleavage fractures and smallest dimensions (at the level of 25-35 $\mu \mathrm{m}$ ) of the cleavage fracture. Thus, more energy can be absorbed during impact. Therefore, the impact toughness is higher at the LSP-treated surface and decreases along the depth of the GHL as the dimension of the cleavage fracture increases with depth. Thus, the GHL is formed during the laser induced shock. The increased number of cleavage fractures and decreased dimension of the cleavage fractures are due to the residual compressive stresses and density of dislocations induced by the laser shock wave. It was reported by Trdan et al. [26] that a shock wave generates residual compressive stresses to a depth of above $0.78 \mathrm{~mm}$, and density of dislocations with various types, including dislocation cells, dislocation lines, dislocation tangles, and the formation of dislocation walls for the $\mathrm{Al}-\mathrm{Mg}-\mathrm{Si}$ alloy. At the same time, the microstructure of the material is rather refined due to the effect of strain deformations induced by the LSP process. As a result, the impact toughness increases 
because of the increased number and decreased dimensions of the cleavage fractures.

\section{Conclusions}

The Cr5Mo1V steel was processed by laser shock peening, and a GHL was exhibited. A new method to estimate the impact toughness that considers the GHL was proposed. When assuming a linearly gradient distribution for impact toughness, the parameters describing the impact toughness of the peened layer were provided. The influences of the laser power densities and number of laser shots on the impact toughness were investigated. The impact toughness of the laser peened layer improves when compared with untreated specimens, and increases in the laser power densities and decreases in the number of laser shots also improve the toughness. Through the fracture morphology analysis by SEM, we established that the Cr5Mo1V steel was fractured by a cleavage mechanism combined with a few dimples. The increase in the impact toughness of the material after LSP results from the cleavage fracture with smaller dimensions and increased fraction component in the fracture process. Therefore, Cr5Mo1V steels with higher impact toughness can be prepared with LSP for applications in the roll industry.

Acknowledgments The project was supported by the National Natural Science Foundation of China (Grants 11002150, 11332011, and 11402277) and the Basic Research Equipment Project of the Chinese Academy of Sciences (YZ200930) for financial support.

\section{References}

1. Montross, C.S., Wei, T., Ye, L., et al.: Laser shock processing and its effects on microstructure and properties of metal alloys: a review. Int. J. Fatigue 24, 1021-1036 (2002)

2. Peyre, P., Fabbro, R.: Laser shock processing: a review of the physics and applications. Opt. Quantum Electron. 27, 1213-1229 (1995)

3. Zhang, Y.K., Lu, J.Z., Luo, K.Y.: Laser Shock Processing of FCC Metals, 1st edn. Springer, Berlin (2013)

4. Yasnii, P.V., Marushchak, P.O., Nikiforov, Y.M., et al.: Influence of laser shock-wave treatment on the impact toughness of heatresistant steels. Mater. Sci. 46, 425-429 (2010)

5. Shukla, P.P., Lawrence, J.: Fracture toughness modification by using a fibre laser surface treatment of a silicon nitride engineering ceramic. J. Mater. Sci. 45, 6540-6555 (2010)

6. Kong, D.J., Zhang, L.: Effects of laser quenching on impact toughness and fracture morphologies of 40CrNiMo high strength steel. J. Mater. Eng. Perform. 23, 3695-3702 (2014)

7. Liao, J.S., Hotta, M., Kaneko, K., et al.: Enhanced impact toughness of magnesium alloy by grain refinement. Scripta Mater. 61, 208$211(2009)$
8. Chaudhury, J.N.: Effect of heat treatment, pre-stress and surface hardening on fracture toughness of micro-alloyed steel. J. Mater. Eng. Perform. 23, 152-168 (2014)

9. Mats, A.V., Netesov, V.M., Sokolenko, V.I.: Dislocation structure and impact toughness of reactor pressure vessel steel 15Kh2NMFA upon ultrasonic treatment. Strength Mater. 43, 515-518 (2011)

10. Peyre, P., Fabbro, R., Merrien, P., et al.: Laser shock processing of aluminium alloys. Application to high cycle fatigue behaviour. Mater. Sci. Eng. A 210, 102-113 (1996)

11. Dane, C.B., Hackel, L.A., Daly, J., et al.: Laser peening of metalsenabling laser technology. Adv. Mater. Process. 5, 13-27 (1997)

12. Wang, X., Xia, W.G., Wu, X.Q., et al.: Microstructure and mechanical properties of an austenite NiTi shape memory alloy treated with laser induced shock. Mater. Sci. Eng. A 578, 1-5 (2013)

13. GB/T229-2007: Standard Test Method for Charpy Pendulum Impact of Metallic Materials. Standards Press of China, Beijing (2007). (in Chinese)

14. Zhou, P.C., Feng, A.X., Nie, G.F., et al.: Impact toughness of $2 \mathrm{Cr} 13$ martensite stainless steel induced by laser. Laser Infrared 42, 1235 1238 (2012). (in Chinese)

15. Marushchak, P.O., Bishchak, R.T., Gliha, B., et al.: Influence of temperature on the impact toughness and dynamic crack resistance of 25Kh1M1F steel. Mater. Sci. 46, 568-572 (2011)

16. Zhang, N., Shi, Y.W., Xia, Z.D., et al.: Comparison of impact toughness and fracture morphologies between $\mathrm{Pb}$-containing and $\mathrm{Pb}$-free solder joints subject to the Charpy impact test. J. Electron. Mater. 37, 1631-1639 (2011)

17. Barbangelo, A.: Influence of alloying elements and heat treatment on impact toughness of chromium steel surface deposits. J. Mater. Sci. 25, 2975-2984 (1990)

18. Buirette, C., Huez, J., Gey, N., et al.: Study of crack propagation mechanisms during Charpy impact toughness tests on both equiaxed and lamellar microstructures of Ti-6Al-4V titanium alloy. Mater. Sci. Eng. A 618, 546-557 (2014)

19. Yang, X.L., Xu, Y.B., Tan, X.D., et al.: Influences of crystallography and delamination on anisotropy of Charpy impact toughness in API X100 pipeline steel. Mater. Sci. Eng. A 607, 53-62 (2014)

20. Demirci, M.T., Tarakcioglu, N., Avci, A., et al.: Fracture toughness of filament wound BFR and GFR arc shaped specimens with Charpy impact test method. Compos. B 66, 7-14 (2014)

21. Chen, X., Yan, J., Karlsson, A.M.: On the determination of residual stress and mechanical properties by indentation. Mater. Sci. Eng. A 416, 139-149 (2006)

22. Carlsson, S., Larsson, P.L.: On the determination of residual stress and strain fields by sharp indentation testing.: Part I: theoretical and numerical analysis. Acta Mater. 49, 2179-2191 (2001)

23. Fabbro, R., Fournier, J., Ballard, P., et al.: Physical study of laserproduced plasma in confined geometry. J. Appl. Phys. 68, 775-784 (1990)

24. Ballard, P., Fournier, J., Fabbro, R., et al.: Residual stresses induced by laser-shocks. J. Phys. IV 1, 487-494 (1991)

25. Masse, J.E., Barreau, G.: Surface modification by laser induced shock waves. Surf. Eng. 11, 131-132 (1995)

26. Trdan, U., Skarba, M., Grum, J.: Laser shock peening effect on the dislocation transitions and grain refinement of $\mathrm{Al}-\mathrm{Mg}-\mathrm{Si}$ alloy. Mater. Charact. 97, 57-68 (2014)

27. Clauer, A., Fairand, B.: Interaction of laser-induced stress waves with metals. In: Metzbower, E. (ed.) Metals Park, pp. 291-315. American Society for Metals, Ohio (1979)

28. Ding, K., Ye, L.: Simulation of multiple laser shock peening of a 35CD4 steel alloy. J. Mater. Process. Technol. 178, 162-169 (2006) 